\title{
In vitro cultivation of Tamarindus indica L.: explants obtention and contamination in culture medium
}

\author{
Antonio Flávio Arruda Ferreira1*, Laís Naiara Honorato Monteiro², \\ Maria Gabriela Fontanetti Rodrigues ${ }^{3}$, Natália Batista Oliveira ${ }^{4}$, Aparecida Conceição Boliani ${ }^{4}$
}

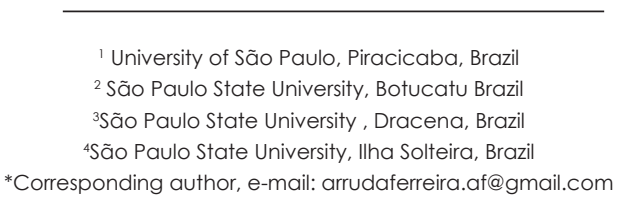

\begin{abstract}
The tamarind tree (Tamarindus indica L.) is a common tree in tropical countries with a great exploitation potential due to its high nutritional value and important pharmaceutical characteristics, justifying its potential as a promising crop. The scarcity of scientific studies of the species, especially on propagation, hinders its availability and, consequently, the supply of the product in the market. The aim of this study was to verify the obtainment of nodal segments via sexual propagation and the in vitro establishment of sweet tamarind in MS culture medium $\left(25,50,75\right.$ and $100 \%$ of salts) and with or without activated charcoal (2 g. $\left.\mathrm{L}^{-1}\right)$. The experiment was carried out in a completely randomized design in a $2 \times 4$ factorial scheme (presence and absence of activated carbon $x$ salt concentrations), with 25 replicates, each replicate consisting of a test tube with an inoculated explant. According to the results, it is possible to conclude that from seedlings with 45 days after sowing, nodal segments of sweet tamarind are obtained for in vitro establishment. As a precursor of protocol for in vitro formation of healthy seedlings is indicated the use of MS culture medium with $75 \%$ of the salts and added with $2 \mathrm{gL}^{-1} \mathrm{of}_{\text {activated }}$ charcoal to reduce the contamination index.
\end{abstract}

Keywords: Tamarind, tissue culture, exotic fruit tree, salt concentration, active charcoal

characterized by the diversification of production and with economic, social and nutritional roles, with special relevance in Brazil, where, given its relative extension when compared to other countries, it is possible to grow temperate, tropical and subtropical species.

Tamarind tree (Tamarindus indica L.) is an arboreal fruit tree belonging to the Fabaceae family, native from Africa. It is currently cultivated in several countries in humid and arid tropical regions (Ajiboye et al., 2010), with medicinal importance, mainly due to its high anti-oxidant activity (Razali et al., 2015).

The tamarind tree is widely used including its bark, leaves, fruits, seeds and roots, as a pharmaceutical ingredient, food for human and animals, etc (Semenzato et al., 2014). The fruit is its most consumed portion, containing vitamins, tartaric and malic acids, sugars and due to the bittersweet taste, it is used as spice and as an ingredient in food products such as beverages, gravies, hot sauces, and worcestershire's sauce. It is also used as wood and animal feed source (Pereira et al., 2008).

Despite its several uses, only a few studies regarding the tamarind tree seedlings production can be found, which occurs by seeds and sexual propagation (Buyinza et al., 2010). However, plant propagation by seeds presents the disadvantage 
of juvenility, which may lead to more than seven years to start the fruit production.

Techniques aiming at reversing the mature stage of woody plants into juveniles, called rejuvenation, or at returning the plant to a high physiological vigor, named reinvigoration (Bonga \& Von Aderkas, 1983), are employed to induce the growth of juvenile buds and to increase the number of propagules with larger rooting potential.

Thus, vegetative propagation with the use of micropropagation is an option to reduce the time to start fruit production and to produce healthy seedlings with higher yield (Dantas et al., 2012). The establishment is the stage where the explants are established in vitro for the subsequent multiplication, rooting, and seedlings production experiments.

For in vitro establishment beyond concentrations of culture media, which influence cell growth, activated charcoal, when used, has a capacity to reduce the oxidation of explants and has been widely used in tissue culture of woody plants (Fermino Junior \& ScherwinskiPereira, 2012).

However, one of the main problems during this cultivation stage is the contamination mainly by endogenous bacteria and fungi, which grow slowly and diffuse on the explants after establishment or during the multiplication stage, reducing or impairing the plantlets growth in field condition (Montovani et al., 2007).

In this context, studies involving the processes of germination and initial development of plantlets for vegetative propagation using tissue culture are important to assure high-quality seedlings and to promote the species cultivation
(Koné et al., 2015).

Considering the Tamarind tree as a crop with potential to expand, the aim of the present study was to assess the feasibility of obtention of nodal segments by sexual propagation for in vitro cultivation of sweet tamarind, evaluating the fungi and bacteria contamination in MS culture medium, with different salt concentrations and with or without active charcoal.

The experiment was carried on between November and December of 2015 in

a Pad\&Fan greenhouse, with average temperature and relative humidity of $25.6^{\circ} \mathrm{C}$ and $76 \%$, respectively. The sweet tamarind fruits were harvested at the end of the maturation stage, in Ilha Solteira - SP, Brazil, located at 20²4'04" of latitude $S$ and $51^{\circ} 20^{\prime} 55^{\prime \prime}$ of longitude $W$, and altitude around $320 \mathrm{~m}$. The climate is Aw, according to Köppen-Geiger's classification, with annual average temperature of $24.5 \pm 3^{\circ} \mathrm{C}$.

The flesh of the collected fruits were obtained using a sieve ( $3 \mathrm{~mm}$ ) and running water. The seeds were dried in shade on absorbent paper, at room temperature $\left(26^{\circ} \mathrm{C}\right)$ for two days (Figure 1a), followed by the sowing in 72-wells polyethylene trays filled with fine grade exfoliated vermiculite (Figure 1b). The seeds were sown, one per well, in a total of 248 seeds, irrigated twice a day using suspended micro-sprinkler with an average flow rate of $1800 \mathrm{~cm}^{3} \mathrm{~min}^{-1}$ for 5 minutes.

The initial emergence index and the emergence 45 days after the sowing (Figure 1c), the length of the aerial part $(\mathrm{cm})$, the stem diameter $(\mathrm{mm})$, the number of leaf pairs and the average number of nodal segments were evaluated in an experimental design with four repetitions and five plantlets per repetition.

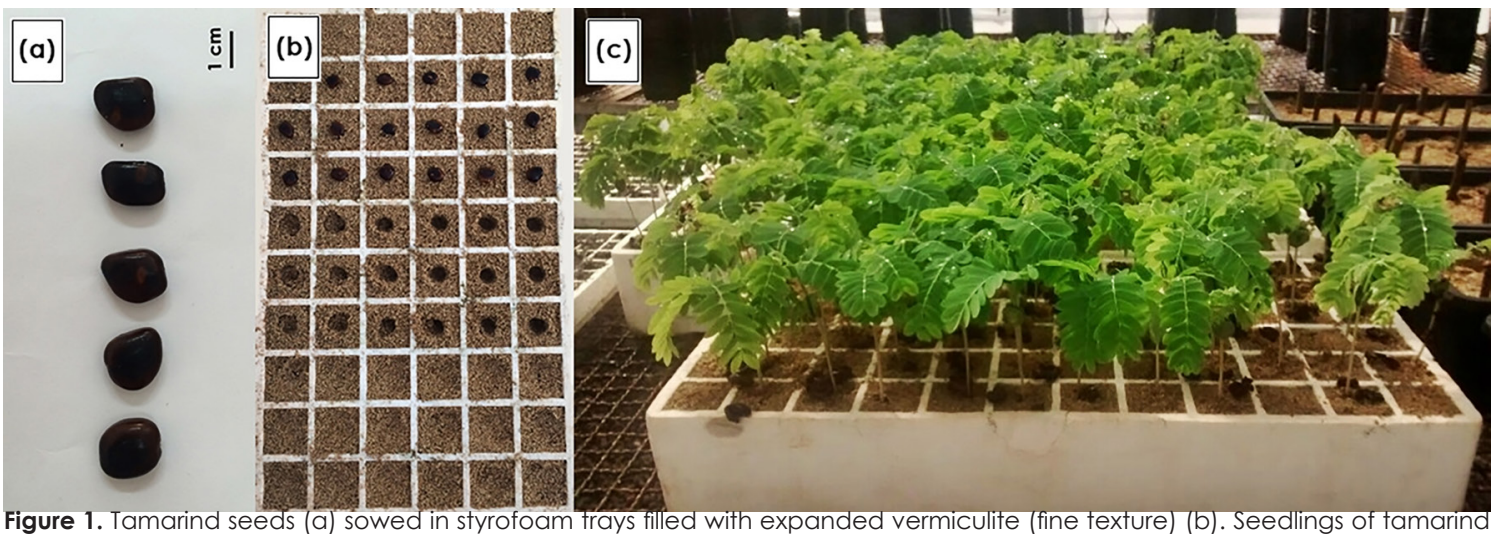

45 days after sowing (c). Ilha Solteira (SP), Brazil, 2016 
The nodal segments were collected with approximately $1 \mathrm{~cm}$ of length with one bud each, from 45 days after sowing. The nodal segments were immersed in $70 \%$ ( $v: v)$ alcohol for one minute, then in a $1 \%$ active chlorine solution $\left(\mathrm{Qboa}^{\circledR}\right)$ added three drops of neutral detergent (Tween 20 ${ }^{\circledR}$ ) for 30 minutes. A triple washing was performed in a laminar flow cabinet using autoclaved distilled water to remove the residue of the used products.

Following the triple washing, the nodal segments were vertically inoculated in test tubes $(2.5 \times 15 \mathrm{~cm})$ with $20 \mathrm{~mL}$ of culture medium, sealed with plastic caps and kept in a growth room under 16-hours photoperiod, temperature of 25 $\pm 3^{\circ} \mathrm{C}$, relative humidity of $45 \pm 0.5 \%$, and active photosynthetic radiation of $45-55 \mu \mathrm{mol} \mathrm{m} \mathrm{m}^{-2} \mathrm{~s}^{-1}$.

The control solution (control) was distilled water solidified with $3.5 \mathrm{~g} \mathrm{~L}^{-1}$ of agar, with $\mathrm{pH}$ adjusted as $5.7 \pm 0.3$ and autoclaved for 20 minutes at $1 \mathrm{Kgf}^{-3}$ and $121{ }^{\circ} \mathrm{C}$. Treatments consisted of culture media containing 25, 50, 75 and $100 \%$ of salts in MS medium (Murashige and Skoog 1962) with and without active charcoal $\left(2 \mathrm{~g} \mathrm{~L}^{-1}\right)$. The treatments were added of vitamins as suggested by White (1943), $30 \mathrm{~g} \mathrm{~L}^{-1}$ of sucrose, adjusted $\mathrm{pH}$ of $5.7 \pm 0.3$ and solidified with $3.5 \mathrm{~g}^{\mathrm{L}-1}$ of agar. Then the medium was autoclaved for 20 minutes at $1 \mathrm{Kgf} \mathrm{cm}^{-3}$ and $121^{\circ} \mathrm{C}$.

The experiment was set in a completely randomized design, with a $2 \times 4$ factorial scheme (presence or absence of active charcoal $x$ salt concentration), with 25 repetitions, represented by a test tube with one inoculated explant. After 30 days, the percent of tubes with microorganisms contamination was determined, and the averages were submitted to Tukey's test at $5 \%$ of significance using the software SISVAR 5.6.

Literature suggests that the average time for the tamarind seed germination is 13 days (ElSiddig et al. 2006), but it may last up to one month. It is also reported that the seeds germinative capacity can vary from 35 to $95 \%$ (Costa et al., 2012). However, Queiroz et al. (2011) noticed that the tamarind plantlets emergence process begins 6 days after sowing and lasts for 17 days, with an average of $91.60 \%$, corroborating with the results described by Pereira et al. (2008), using seed scarification and 24 hours immersion.

From the 248 evaluated sweet tamarind seeds, $92.7 \%$ of the plantlets emerged at the 7th day after sowing, corroborating the data obtained by Queiroz et al. (2011), even without the seeds scarification and soaking.

Regarding the aerial part length and stem diameter of the sweet tamarind plantlets, only the plants between 30 to $40 \mathrm{~cm}$ height and with a diameter of $4.0 \mathrm{~mm}$ after 45 days of sowing are considered viable according to Pereira et al. (2008) (Table 1).

Table 1. Shoot length (SL), stem diameter (SD), leaf pairs (LP) and the number of nodes (NN) of sweet tamarind seedlings. Ilha Solteira (SP), Brazil, 2016

\begin{tabular}{ccccc}
\hline REP & SL $(\mathrm{cm})$ & SD $(\mathrm{mm})$ & LP & NN \\
\hline I & $24.40^{\mathrm{ns}}$ & $2.46^{\text {ns }}$ & $11.20^{\text {ns }}$ & $5.00^{\text {ns }}$ \\
II & 22.70 & 2.44 & 11.20 & 5.00 \\
III & 22.50 & 2.65 & 12.20 & 5.40 \\
IV & 25.90 & 2.64 & 11.20 & 4.80 \\
\hline Average & 23.88 & 2.55 & 11.45 & 5.05 \\
\hline
\end{tabular}

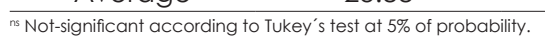

After 45 days of sowing, in average, the plantlets presented $23.88 \mathrm{~cm}$ in length and 2.55 $\mathrm{mm}$ of diameter, which is considered below the adequate for field sowing. However, the average numbers of leaf pairs (11.4) and nodal segments (5) were appropriate for the in vitro implantation of the species. In addition, according to Ferreira (2014), the use of nodal segments in micropropagation is growing, mainly with woody species in the Fabaceae family.

The number of nodal segments of the sweet tamarind contaminated by pathogens incubated in MS culture medium, with or without activate charcoal is presented in Table 2.

The control treatments (without salt) and with or without active charcoal addition presented, at 30 days, no regeneration of the aerial part or callogenesis in the tamarind explants, as observed by Ferreira (2014). Thus, since there was no incidence of pathogens, it is possible to conclude that the explants disinfestation was satisfactory. 
Table 2. Contamination (fungi and bacterial) of nodal segments of sweet tamarind inoculated in culture media with different salt concentrations. Ilha Solteira, SP, Brazil, 2016

\begin{tabular}{ccc}
\hline \multirow{2}{*}{ Salt Concentration (\%) } & \multicolumn{2}{c}{ CONTAMINATION (\%) } \\
\cline { 2 - 3 } & MS + CA** & MS \\
\hline Control & $0 \mathrm{a}^{*}$ & $0 \mathrm{a}$ \\
25 & $28 \mathrm{~b}$ & $12 \mathrm{C}$ \\
50 & $24 \mathrm{~b}$ & $20 \mathrm{~d}$ \\
75 & $0 \mathrm{a}$ & $20 \mathrm{~d}$ \\
100 & $0 \mathrm{a}$ & $8 \mathrm{~b}$ \\
\hline Contamination Index & $50 \% \mathrm{~A}$ & $100 \% \mathrm{~B}$ \\
\hline "Same lower case letters in the same column and uppercase letters in lines: means are not statistically different according to Tukey's test at 5\% \\
of probability.* ${ }^{* *} \mathrm{MS}+\mathrm{CA}=$ MS medium with activated charcoal.
\end{tabular}

At the 30th day of cultivation, in the presence of salt and active charcoal, the nodal segments were contaminated by fungi and bacteria in the concentrations of 25 and $50 \%$ of salt, whereas in the concentrations of 75 and $100 \%$ of salt, there was no contamination. It is possible to observe that the salts included in the culture media have a nutritional role, and influence cellular growth and morphogenesis due to the osmotic properties.

The nodal segments inoculated in the culture medium without active charcoal, regardless the salt concentration, showed contamination by pathogens, showing that both the salt concentration and the presence of active charcoal influence the explants response to harmful pathogens. On the other hand, the active charcoal can adsorb toxic substances released by the explants or impurities from other components, avoiding contamination by endogenous fungi and bacteria (Fermino Junior \& Scherwinski-Pereira 2012).

With the results obtained it is concluded that 45 days after sowing, seedlings presented an average of 5 nodal segments of sweet tamarind per plant. As a precursor of protocol for the in vitro production of healthy seedlings is indicated the use of MS culture medium with $75 \%$ of salts and added with $2 \mathrm{~g} \mathrm{~L}^{-1}$ of activated charcoal.

\section{References}

Ajiboye, A.A., Agboola, D.A., Atayese, M.A. 2010. Seed germination and peroxidase analysis of some valuable savanna tree seed species. The Pacific Journal of Science and Technology 11: 463-470.

Bonga, J.M., Von Aderkas, P. 1992. In vitro culture of trees. Kluwer Academic Publishers, Netherlands. 236 p.
Buyinza, M., Senjonga, M., Lusiba, B. 2010. Economic valuation of a tamarind (Tamarindus indica L.) production system: Green money from drylands of eastern Uganda. Small-scale Forestry 9: 317-329.

Costa, E., Ferreira, A.F.A., Silva, P.N.L., Nardelli, E.M.V. 2012. Diferentes composições de substratos e ambientes protegidos na formação de mudas de pé-franco de tamarindeiro. Revista Brasileira de Fruticultura 34: 1189-1198.

Dantas, A.C.V.L. Queiroz, J.M.O., Vieira, E.L., Almeida, V.O. 2012. Effect of gibberellic acid and the biostimulant Stimulate ${ }^{\circledR}$ on the initial growth of tamarind. Revista Brasileira de Fruticultura 34: 8-14.

El-Siddig, K., Gunasena, H. P. M., Prasa, B. A., Pushpakumara, D. K. N. G., Ramana, K. V. R., Vijayanand. P., Williams, J. T. 2006. Tamarind - Tamarindus indica L. Fruits for the future 1. Southampton Centre for Underutilized Crops, Southampton, United Kingdom. 188p.

Fermino Junior, P. C. P., Scherwinski-Pereira, J. E. 2012. Germinação e propagação in vitro de cerejeira (Amburana acreana (Ducke) A.C. Smith - Fabaceae). Revista Ciência Florestal 22: $1-9$.

Ferreira, A.F.A. Propagação vegetativa de Tamarindus indica L. 2014. 95f. (Dissertação de Mestrado) - Universidade Estadual Paulista, Ilha Solteira, Brasil.

Koné, M., Koné, T., Silué, N., Soumahoro, A.B., Kouakou, T.H. 2015. In Vitro seeds germination and seedling growth of bambara groundnut (Vigna subterrânea (L.) Verdc. (Fabaceae)). The Scientific World Journal 2015: 1-8.

Montovani, N., Otoni, W.C., Grando, M.F. 2007. Produção de explantes através da alporquia para o cultivo in vitro do urucum (Bixa orellana L.). Revista Brasileira de Biociências 5: 597-599.

Murashige, T.; Skoog, F. 1962. A revised medium for rapid growth and bioassays with tabacco tissue culture. Physiologia Plantarum 15: 473-497. 
Pereira, P.C., Freitas, R.S., Melo, B., Franzão, A.A., Pereira, A.P., Santana, J.G., LUz, J.M.Q., Martins, M. 2008. Influência do tamanho de sementes na qualidade de mudas de tamarindeiro. Bioscience Journal 24: 73-79.

Queiroz, J.M.O., Dantas, A.C.V.L., Almeida, V.O., Barroso, J.P. 2011. Emergência de plântulas e crescimento inicial de tamarindeiro em diferentes substratos. Magistra, 23: 221-227.

Razali, N., Junit, S.M., Ariffin, A., Ramli, N.S.F., Aziz, A.A. 2015. Polyphenols from the extract and fraction of $T$. indica seeds protected HepG2 cells against oxidative stress. BMC Complementary Alternative Medicine 15: 438.

Semenzato, A., Costantini A., Baratto, G. 2014. Green polymers in personal care products: rheological properties of tamarind seed polysaccharide. Cosmetics 2: 1-10.

White, P.R. 1943. Nutrient deficiency studies and an improved inorganic nutrient medium for cultivation of excised tomato roots. Plant Growth Regulation 7: 53-65. 